\title{
DESAFIOS DA ÁREA DE PROTEÇÃO AMBIENTAL EM TERRITÓRIO INSULAR: PROPOSIÇÃO DE PLANEJAMENTO PARA GESTÃO DE RECURSOS HÍDRICOS SOB A PERSPECTIVA DOS MORADORES DA ILHA DO COMBU, BELÉM, PARÁ
}

CHALLENGES OF THE ENVIRONMENTAL PROTECTION AREA IN ISLAND TERRITORY: PROPOSITION OF PLANNING FOR MANAGEMENT OF WATER RESOURCES UNDER THE PERSPECTIVE OF THE PEOPLE OF COMBU ISLAND, BELÉM, PA, BRAZIL

\section{Salma Saráty de Carvalho}

Doutoranda na Universidade Federal do Pará (UFPA), Programa de PósGraduação em Ciências Ambientais (PPGCA). Docente na Universidade Federal Rural da Amazônia (UFRA) Capanema (PA), Brasil.

\section{Marcia Aparecida da Silva Pimentel}

Docente na Universidade Federal do Pará (UFPA), Programa de PósGraduação em Ciências Ambientais (PPGCA) - Belém (PA), Brasil.

\section{Aline M. Meiguins de Lima (D)}

Docente na Universidade Federal do Pará (UFPA), Programa de PósGraduação em Ciências Ambientais (PPGCA) - Belém (PA), Brasil.

\section{Endereço para correspondência:}

Salma Saráty de Carvalho Universidade Federal Rural da Amazônia - Laboratório de Modelagem Moleculare Simulação de Sistemas - Avenida Barão de Capanema, s/n. Caixa d'Água - CEP 68700-665 Capanema (PA), Brasil - E-mail: salma.meioambiente@gmail.com

Recebido em: 05/03/2019

Aceito em: 27/05/2019

\section{RESUMO}

O propósito das Unidades de Conservação (UCs) consiste em garantir o desenvolvimento sustentável de uma área que apresenta diversidade biológica e conhecimento tradicional, contribuindo para a redução da vulnerabilidade socioambiental. $\mathrm{O}$ trabalho evidencia os aspectos inerentes ao conceito de desenvolvimento sustentável, Área de Proteção Ambiental (APA) e recursos hídricos, direcionando esse contexto para a realidade dos moradores da APA da Ilha do Combu no município de Belém, Pará. O objetivo desta investigação foi analisar os desafios da APA insular sob a percepção dos moradores locais, propondo um planejamento para gestão de recurso hídrico que colaborasse com o desenvolvimento sustentável nessa área. Houve a caracterização das principais problemáticas vinculada a referida UC e, posteriormente, avaliou-se a efetividade do uso da água e sustentabilidade sugerindo um planejamento de gestão hídrica. Os resultados apontaram algumas complexidades típicas de APA de uma ilha, fato que refletiu na definição das metas prioritárias sugeridas no planejamento.

Palavras-chave: unidade de conservação; vulnerabilidade; biodiversidade; sustentabilidade.

\section{ABSTRACT}

The purpose of Conservation Units (UC) is to ensure the sustainable development of an area that presents biological diversity and traditional knowledge, contributing to the reduction of socio-environmental vulnerability. This work presents the inherent aspects of sustainable development, Environmental Protection Area (EPA) and water resources, directing this context to the reality of the EPA residents of the Combu Island in the municipality of Belém, Pará. The objective of this research was to analyze the challenges of the insular EPA under the perception of the local inhabitants, proposing a plan for managing the water resources that collaborate with the sustainable development in this area. There was a characterization of the main problems linked to this UC and, later, the method of Mejía et al. (2012) was used as a suggestion of a water management plan. The results pointed to some typical APA complexities of an island; a fact that reflected in the definition of the priority goals suggested in the planning.

Keywords: conservation unit; vulnerability; challenges, biodiversity; sustainability. 


\section{INTRODUÇÃO}

Nos últimos anos, a aceleração do uso dos recursos naturais tem desencadeado diversos impactos nos meios físico, biótico e socioeconômico em diferentes escalas, de tempo e espaço, graus de importância e reversibilidade.

Tal fato vem despertando cada vez mais a necessidade de integração entre a sociedade, poder público e instituições de ensino e pesquisa para tratar os problemas no meio ambiente, visando a garantia de continuidade de todas as formas de vida (SANTOS et al., 2016).

O incremento no acesso e uso do recurso hídrico e a biodiversidade vêm levantando questionamentos sobre a capacidade de suporte associados a níveis de vulnerabilidade dos ecossistemas e das ocupações afetadas. Nesse sentido, as iniciativas técnico-científico-jurídicas têm caráter relevante para assegurar a contribuição e/ ou solução de problemáticas relacionadas à alteração da qualidade ambiental e dos recursos hídricos.

No Brasil, entre os dispositivos legais que objetivam garantir a qualidade ambiental e hídrica, tem-se a Lei do Sistema Nacional de Unidade de Conservação (SNUC; Lei no 9.985 - BRASIL, 2000) e a Política Nacional de Recursos Hídricos (Lei no 9.433/97). Ambas constituem em iniciativas para garantir a conservação e preservação de territórios dotados de água, biodiversidade e conhecimentos tradicionais.

A criação e manutenção de Unidades de Conservação (UCs) tem o propósito de proteger a biodiversidade em um determinado território e, nesse contexto, a sua efetividade não está associada somente à categoria de proteção, pois deve ser vinculada a uma gestão democrática e competente que permita, no contexto atual e futuro, o alcance da qualidade de vida da população, dos recursos naturais (bióticos e abióticos), proteção do patrimônio genético (MARQUES et al., 2017), serviços ecossistêmicos e conhecimento tradicional associado.

A busca pela preservação e/ou conservação de um território legalmente protegido, quando localizado em área fluvial, merece destaque por se tratar de um ecossistema específico composto por mata ciliar e de várzea, biota aquática e ocupações, predominantemente, de população ribeirinha (LEAL et al., 2016).

Considerando que os desafios da UC estão relacionados à reduzida participação da população e à carência de uma boa governança (ABRAHÃO; ASMUS; FERREIRA, 2019), verifica-se que a UC, na perspectiva de um território fluvial, pode apresentar desafios diferenciados, pois, além da necessidade de proteção da biodiversid de terrestre, a UC deve priorizar ações de sustentabilidade ambiental para manter a integridade da propriedade da água. Tais esforços buscam evitar que o processo de perturbação e os impactos ambientais desencadeados possam comprometer o propósito da UC e a sustentabilidade hídrica do território (MUSTIN et al., 2017).

A Ilha do Combu consiste em uma UC na categoria de Área de Proteção Ambiental (APA), localizada no município de Belém, no Estado do Pará, que foi criada com objetivo de promover a sustentabilidade de seus recursos ambientais e garantir a qualidade de vida da população.

Considerando as características de uma área fluvial, tornou-se relevante analisar os desafios da APA insular sob a ótica dos moradores locais e propor um planejamento para gestão de recurso hídrico como contribuição para o alcance do propósito da UC nessa localidade.

\section{Aspectos sobre o desenvolvimento sustentável, sustentabilidade e recursos hídricos}

A consolidação do conceito de desenvolvimento sustentável (DS) ocorreu na publicação do Relatório Brundtland, em 1987, intitulado como Our Common Future, que destacava que esse tipo de desenvolvimento deveria considerar três bases fundamentais: crescimento econômico, equidade/justiça social e preservação/conservação dos recursos naturais no ambiente (CAMARGO, 2016). Assim, o DS deveria garantir a qualidade de vida para gerações atuais e futuras, sem prejudicar as possibilidades de sustentação da sociedade por longos períodos (STOFFEL; COLOGNESE, 2015).

Vários debates têm avaliado o conceito de DS, principalmente em relação a quais aspectos poderão ser considerados para garantir equidade e justiça para as gerações atual e futura (TODOROV; MARINOVA, 2009). Para Dovers e Handmer (1992), o conceito de DS evoluiu como um entendimento integrador, em que diversas questões podem ser associadas a essa definição simultaneamente. 
Por outro lado, outros autores destacam que o conceito de DS não expressa apropriadamente as estratificações das dimensões econômica, social e ambiental com vista a garantia da qualidade de vida para geração atual ou futura. Essas estratificações deveriam ser evidenciar outros aspectos, como cultural, político (SACHS, 2007; NASCIMENTO, 2012), psicológico, espiritual (BOFF, 2012), ético, ambiental, lutas de classes, entropia (CAMARGO, 2016), sustentabilidade territorial e sustentabilidade ecológica (SACHS, 2009). Salienta-se, ainda, que o enfoque em valores coletivos, coesão e articulação do grupo é indispensável para garantir a sustentabilidade de comunidades locais (TISDELL, 1997).

De acordo com alguns autores, o desafio relacionado ao conceito de DS corresponde a compreender a preferência da geração futura, pois o grau de incerteza poderia refletir em divergências que implicariam na dificuldade de se alcançar a equidade entre gerações (STOFFEL; COLOGNESE, 2015).

Segundo Camargo (2016), o termo DS precisa ser diferenciado de sustentabilidade, já que alguns trabalhos os consideram sinônimos. Segundo Dovers e Handmer (1992), a sustentabilidade seria o objetivo final a ser alcançado proveniente de um processo de mudança, para Prugh e Assadourian (2003), somente se alcança a sustentabilidade a partir do DS.

Alguns autores alertam que o conceito de DS evidencia uma visão antropocêntrica, cuja natureza tem a finalidade de atender o consumo da sociedade em diferentes épocas (CAMARGO, 2016).

Além da discussão sobre a essência do conceito de DS, torna-se importante compreender a respeito do surgimento da expressão sustentabilidade, que, para Nascimento (2012), tem duas origens: a primeira na biologia, quando aborda a ecologia, resiliência dos ecossistemas e as interferências antrópicas; e a segunda na economia, quando se refere a padrões de produção e consumo.

Ao considerar a sustentabilidade como resultado de um processo de DS (PRUGH; ASSADOURIAN, 2003), verifica-se ainda a possibilidade de existir variações que a classifique como fraca ou forte.

De acordo com Sartori, Latrônico e Campos (2014), a sustentabilidade pode ser considerada fraca quando beneficia o crescimento econômico, ou forte quando entendida sob a concepção de não substituição, pre- servando as funções do ambiente. Quando considerado o campo da economia ecológica, entende-se que a sustentabilidade fraca existe quando o destaque é direcionado para pressão sobre o uso dos recursos e a sustentabilidade forte ocorre quando há preservação do capital natural (STOFFEL; COLOGNESE, 2015).

Considerando o propósito das UCs, que trata da promoção do DS, compreende-se que a proteção da biodiversidade em um território busca trazer resultados para a sociedade (MARQUES et al., 2017) e, por isso, deve ser monitorada por indicadores ou, se a categoria permitir, pela percepção dos moradores que revelem a aproximação/distanciamento/cumprimento do objetivo da proteção integral ou de uso sustentável. Nesse sentido, o nível de sustentabilidade poderá ser avaliado por UC, ainda que haja diferentes categorias.

No que tange aos territórios insulares, o estudo da sustentabilidade ambiental precisa incorporar a abordagem referente aos recursos hídricos. Thomas (2002) argumenta que as águas superficiais são consideradas mais vulneráveis à poluição e à escassez, em virtude da facilidade de acesso para lançamento de efluentes domésticos e industriais, principalmente próximos a ocupações urbanas.

Além disso, é característica de áreas fluviais a ocorrência de impactos negativos decorrentes de mudança da qualidade e/ou quantidade de um recurso hídrico, pois se torna mais evidente em localidades nas quais os grupos sociais apresentam intensa desigualdade econômica e a garantia da qualidade de vida já se encontra em elevado nível de vulnerabilidade (VARELA, 2016).

No Brasil, verifica-se que as bases legais ambientais e de recursos hídricos abordam o princípio da precaução e prevenção, objetivando a proteção e recuperação da qualidade ambiental, o que, consequentemente, busca os fundamentos do DS (PIZELLA; SOUZA, 2007).

Em conformidade com o conceito de DS, verificam-se dois instrumentos legais, a Política Nacional de Recursos Hídricos, estabelecida pela Lei no 9.433/97, que define instrumentos regulatórios e econômicos que conduzem à gestão hídrica fundamentada na sustentabilidade (PIZELLA; SOUZA, 2007; FINKLER et al., 2015); e a Lei no 9.985/2000, que institui o Sistema Nacional de Unidades de Conservação da Natureza (SNUC), cujo art. 4오 se refere aos objetivos, entre eles, a proteção dos recursos hídricos (BRASIL, 2014). 
Corroborando esses propósitos, no âmbito internacional, a Resolução do Conselho das Nações Unidas no $64 / 292$, de setembro de 2010 , declara como sendo fundamentais para o humano garantir a qualidade de vida e, por isso, deve ser garantido o direito de acesso à água limpa e segura com saneamento (CORREIA, 2013), agregando nessa gestão o princípio da justiça social em relação ao acesso à água potável e ao saneamento adequado para população.

Torna-se imprescindível que as discussões a respeito da sustentabilidade hídrica em uma localidade considerem articulações políticas integradas, com a participação de todos os interessados, visando abordar questões sobre as relações energia/água, qualidade/ quantidade de água, infraestrutura verde e manejo de bacias hidrográficas. Por outro lado, o debate sobre a sustentabilidade hídrica precisa, portanto, referenciar a existência ou não de uma relação entre as problemáticas apresentadas nas esferas econômi- cas, ambientais e sociais do território e a questão da água - potável, residual, subterrânea, pluvial e produto de reutilização (HEINTZ JR., 2004; GREGORY; HALL, 2011).

A utilização de sistemas mais eficientes de acesso à água contribui para o alcance da sustentabilidade hídrica e, dessa forma, deveria ser priorizado o uso de fontes locais de água; também, à medida que houvesse o incremento na população, os recursos hídricos deveriam ser alocados, considerando diversos cenários, inclusive de mudanças climáticas (GLEICK, 1998; DALHUISEN et al., 2003; KRANZ et al., 2004; HERING et al., 2015).

Diante do exposto, a sustentabilidade hídrica e ambiental faz-se relevante para qualidade de vida da sociedade e do ambiente, principalmente no que se refere aos territórios fluviais em que comunidades mais vulneráveis fazem uso dos recursos naturais.

\section{Área de Proteção Ambiental como promoção do desenvolvimento sustentável}

A base legal brasileira que rege, especificamente, sobre áreas protegidas corresponde à Lei $n$ ㅇ 9.985, instituída em 18 de julho de 2000, dispõe sobre o Sistema Nacional de Unidade de Conservação (SNUC) (BRASIL, 2000).

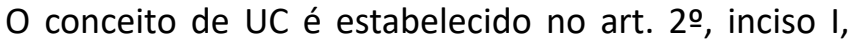
como um espaço territorial instituído pelo poder público que contenha recursos ambientais e águas jurisdicionais, com características expressivas, objetivando a conservação. Sobre as águas jurisdicionais brasileiras, citadas no SNUC, destaca-se que, desde 1993, a Lei Federal no 8.617 já garantia a proteção ao mar territorial, que inclui o litoral continental e insular definidos em cartas náuticas oficiais, e a soberania do Brasil no aproveitamento, gestão e conservação dos recursos naturais (BRASIL, 1993).

Contudo, é no art. 4 que se evidencia o propósito da criação da UC a partir da promoção do DS no uso dos recursos naturais (inciso IV), tornando evidente sua finalidade para o alcance da qualidade ambiental, social e econômica, sendo prevista, portanto, no artigo 50, inciso III, a participação da população local nesse processo.
Entre as categorias de UC estabelecidas como área legalmente protegida, têm-se no art. 70, inciso I e II, a Unidade de Proteção Integral e a Unidade de Uso Sustentável. O parágrafo 1 ㅇ do referido artigo, destaca que a Unidade de Proteção Integral visa a preservação da natureza, podendo os recursos serem utilizados de forma indireta, e o parágrafo 2 o indica que a Unidade de Uso Sustentável propõe conciliar a conservação e uso sustentável da natureza.

Vale ressaltar que a base legal não faz referência à área protegida localizada em território insular, pois a classificação ocorre por categoria de uso e preservação, e não distingue por região de terra firme ou insular.

Diante de tal situação podem sugerir desafios diferenciados para o alcance de uma boa governança e obtenção da sustentabilidade, por envolver outros recursos naturais, como a água e a biota aquática, assim como ocupação ribeirinha, enquanto comunidade tradicional.

Considerando que a categoria Unidade de Uso Sustentável admite o uso racional da natureza e consente diferentes níveis de ocupação humana e/ou atividade produtiva, espera-se que o nível de parti- 
cipação da população na gestão da área protegida seja maior, se comparado com as Unidades de Proteção Integral. Por outro lado, os desafios relacionados à governança podem estar vinculados à dificuldade de integração entre governo, comunidade local e sociedade para atender ao mesmo propósito de sustentabilidade, entretanto, em contextos e prioridades diferenciados.

Entre os territórios relacionados à categoria de Uso Sustentável, têm-se: Área de Proteção Integral, Área de Relevante Interesse Ecológico, Floresta Nacional, Reserva Extrativista, Reserva de Fauna, Reserva de Desenvolvimento Sustentável e Reserva Particular de Patrimônio Natural.
O art. 14, inciso I, refere-se à Área de Proteção Ambiental (APA) como pertencente ao grupo de Unidades de Uso Sustentável, sendo conceituada, no art. 15, como um espaço dotado de riquezas naturais, admitindo ocupações humanas, cujo objetivo consiste na proteção da diversidade biológica, sustentabilidade e organização das ocupações. Nesse aspecto, verifica-se a necessidade de participação popular para a criação, implantação e gestão de UC, conforme indicado no art. 5o e inciso III do SNUC.

No Estado do Pará existem 25 UCs, sendo que 8 delas são APAs (Quadro 1), as quais estão distribuídas nas seguintes regiões administrativas: Belém, Calha Norte I, Calha Norte II, Calha Norte III, Xingu, Marajó, Nordeste,

Quadro 1 - Relação de Unidades de Conservação por Região Administrativa no Estado do Pará.

\begin{tabular}{|c|c|c|c|}
\hline $\mathbf{R A}$ & UC & $\begin{array}{l}\text { Total de } \\
\text { UC por RA }\end{array}$ & $\begin{array}{c}\text { Total de } \\
\text { APAs por RA }\end{array}$ \\
\hline Belém & $\begin{array}{l}\text { Área de Proteção Ambiental da Região Metropolitana de Belém, } \\
\text { Área de Proteção Ambiental da Ilha do Combu, Refúgio de Vida } \\
\text { Silvestre Metrópole da Amazônia e Parque Estadual do Utinga }\end{array}$ & 4 & 2 \\
\hline Calha Norte I & $\begin{array}{l}\text { Parque Estadual de Monte Alegre (PEMA) } \\
\text { e Área de Proteção Ambiental Paytuna }\end{array}$ & 2 & 1 \\
\hline Calha Norte II & $\begin{array}{l}\text { Floresta Estadual de Faro, Floresta Estadual } \\
\text { de Paru e Floresta Estadual de Trombetas }\end{array}$ & 3 & Não tem \\
\hline Calha Norte III & Estação Ecológica do Grão-Pará e Reserva Biológica Maicuru & 2 & Não tem \\
\hline Xingu & $\begin{array}{c}\text { APA Triunfo do Xingu, Floresta Estadual do Iriri, Refúgio de Vida } \\
\text { Silvestre Tabuleiro do Embaubal e Reserva de Desenvolvimento } \\
\text { Sustentável Vitória de Souzel }\end{array}$ & 4 & 1 \\
\hline Marajó & Área de Proteção Ambiental do Marajó e Parque Estadual Charapucu & 2 & 1 \\
\hline Nordeste & $\begin{array}{l}\text { Área de Proteção Ambiental de Algodoal - Maindaeua, Refúgio da } \\
\text { Vida Silvestre Padre Sérgio Tonetto e Reserva de Desenvolvimento } \\
\text { Sustentável Campo das Mangabas }\end{array}$ & 3 & 1 \\
\hline $\begin{array}{l}\text { Mosaico do } \\
\text { Lago Tucuruí }\end{array}$ & $\begin{array}{c}\text { Área de Proteção Ambiental do Lago de Tucuruí, Reserva } \\
\text { de Desenvolvimento Sustentável Alcobaça e Reserva de } \\
\text { Desenvolvimento Sustentável Pucuruí Ararão }\end{array}$ & 3 & 1 \\
\hline Araguaia & $\begin{array}{l}\text { Parque Estadual Serra dos Martírios - } \\
\text { Andorinhas e Área de Proteção Ambiental Araguaia }\end{array}$ & 2 & 1 \\
\hline \multicolumn{2}{|c|}{ Total no Estado do Pará } & 25 & 8 \\
\hline
\end{tabular}

UC: Unidade de Conservação; RA: Região Administrativa; APA: Área de Proteção Ambiental.

Fonte: adaptado de Ideflor-Bio (2018). 
Mosaico do Lago Tucuruí e Araguaia, em que se verifica a existência de APA insular, como, por exemplo, a APA Ilha do Combu.

Quando considerada a existência de ocupações na UC, como é o caso da APA, e quando os problemas apresentados sugerem uma especificidade, APA insular, a análise dos desafios locais precisa contar com a percepção dos moradores.

O método de Mejía et al. (2012), baseado nas definições de water sustainability targets (WSTs, alvos para sustentabilidade hídrica), consiste em um procedimento para avaliar a efetividade do uso da água e sustentabilidade, e, a partir daí, sugere planejamento para gestão de recursos hídricos, o qual estabelece Goal (metas), Target (alvos), Tools (ferramentas) e Indicators (indicadores) (Figura 1):

- Goal (metas): é o objetivo principal para o qual uma intervenção de desenvolvimento pretende contribuir;
- Target (alvos): indica o número, o tempo e a localização do que deve ser realizado, devendo ser mensurável, alcançável, relevante e relacionado ao tempo;

- Tools (ferramentas): são elementos, métodos e abordagens que suportam tomadas de decisão sobre a água e facilitam o alcance dos resultados;

- Indicators (indicadores): são variáveis quantitativas ou qualitativas que fornecem meios simples e confiáveis para medir a realização e avaliar as mudanças associadas a uma intervenção.

A definição das metas consiste no procedimento inicial, o qual está diretamente ligado aos resultados que levarão a determinação de indicadores. 0 desenvolvimento das metas ocorre após a identificação e análise das problemáticas vinculadas à água e à sustentabilidade.
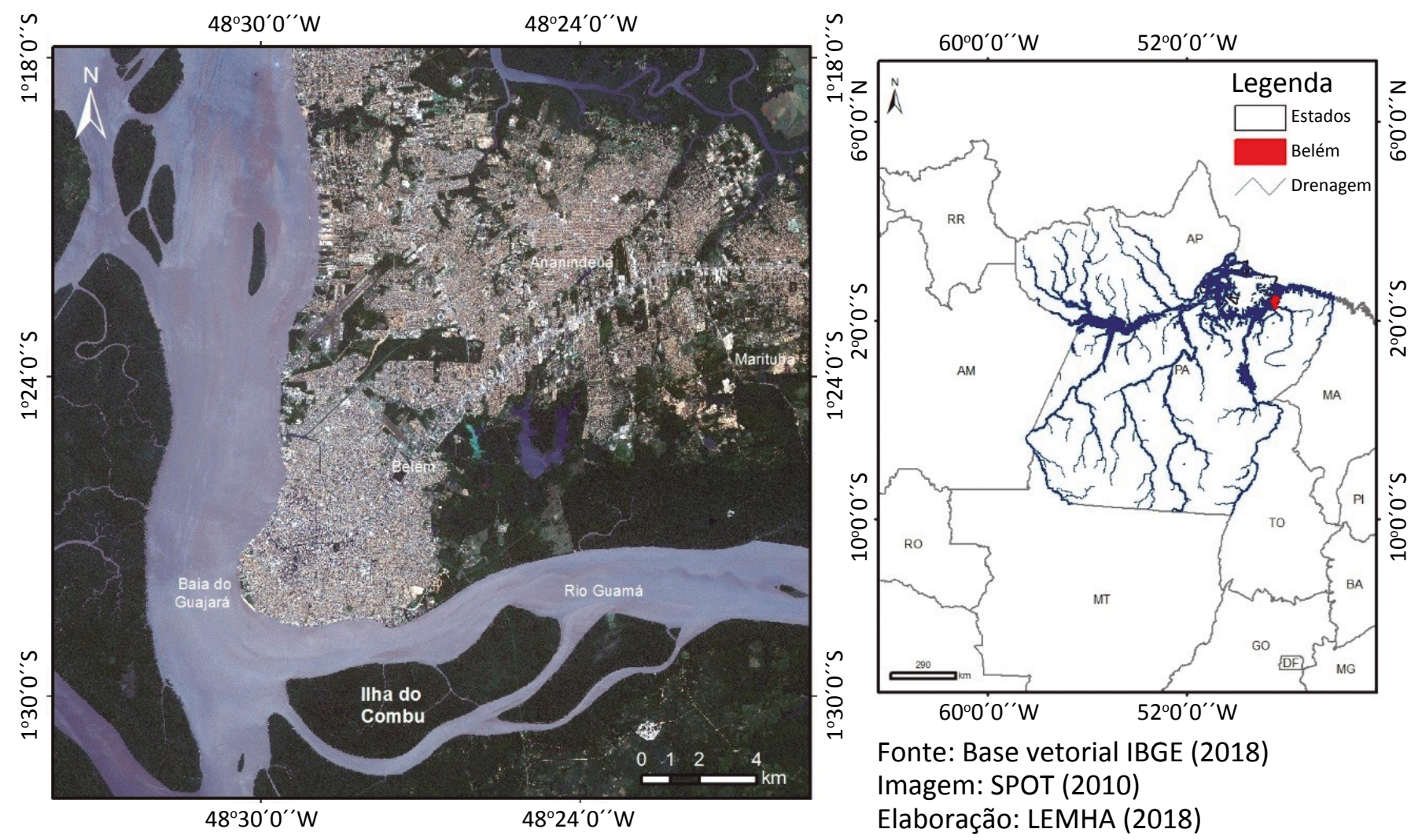

Figura 1 - Localização da Área de Proteção Ambiental (APA) da Ilha do Combu. 


\section{METODOLOGIA}

A pesquisa consistiu em uma abordagem qualitativa buscando analisar os desafios da APA insular na Ilha do Combu, localizada no município de Belém, no Estado do Pará, assim como propor modelo de gestão de recurso hídrico. A APA é formada por um espaço físico correspondente a $15.972 \mathrm{~km}^{2}$, sendo a quarta maior ilha do município de Belém (Figura 2), localizada a $1,5 \mathrm{~km}$ ao sul da cidade, ao norte pelo Rio Guamá, ao sul pelo Furo São Benedito, ao leste pelo Furo da Paciência e ao oeste pela Baía do Guajará (IDEFLOR-BIO, 2018). As ocupações na llha são distribuídas em quatro comunidades: Igarapé Combu, Santo Antônio ou Igarapé Piriquitaquara, Beira Rio e São Benedito a Preser$\operatorname{var}$ (CIRILO, 2013).

Utilizou-se o método de Mejía et al. (2012) para definir metas prioritárias que pudessem contribuir para a sustentabilidade hídrica da APA Insular.

Para definição das metas prioritárias, foi necessário compreender as problemáticas da UC sob a perspectiva dos moradores da localidade, principalmente no que tange à sustentabilidade da APA insular.
As atividades de campo ocorreram em setembro de 2018, na Comunidade Igarapé do Piriquitaquara, onde se utilizou de entrevistas dirigidas considerando os seguintes aspectos-chave:

- saneamento básico;

- formas de uso da água;

- principais dificuldades de acesso à água.

Segundo o Instituto Brasileiro de Geografia e Estatística (IBGE, 2010), na ilha existem 305 domicílios, dois estabelecimentos de ensino e 21 estabelecimentos com outras finalidades, por isso é impreciso determinar a amostragem representativa do universo da Comunidade Igarapé do Piriquitaquara; assim, procurou-se, nas discussões, o diálogo junto às representações que se mostraram disponíveis para responder aos questionamentos.

Foram descritos os principais componentes de análise dos problemas apontados pelos moradores da APA, assim como propostas que poderia contribuir para o
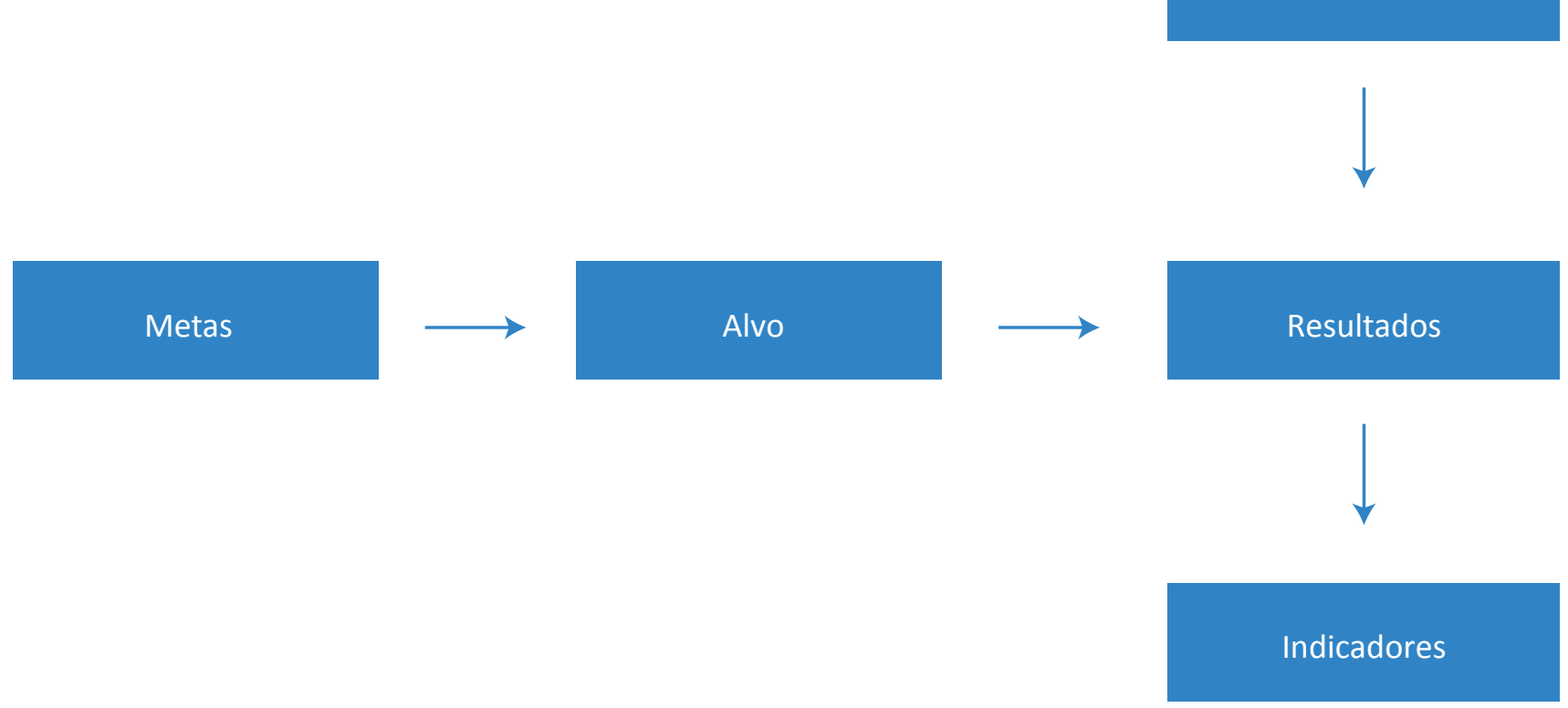

Fonte: adaptado de Mejía et al. (2012).

Figura 2 - Alvos para sustentabilidade hídrica. 
alcance do propósito da APA, por meio do acesso ao recurso hídrico com qualidade.

Com a definição da meta prioritária, seguiu-se com o ciclo de Mejía et al. (2012) para identificação dos alvos, descrição dos resultados na forma de indicadores. A proposição do planejamento para gestão de recursos hídricos teve como base as características específicas dessa APA insular, a partir da percepção dos moradores locais.

\section{RESULTADOS E DISCUSSÃO}

A APA da Ilha do Combu foi criada pela Lei Estadual no 6.083, de 13 de novembro de 1997, e está sob gestão da Secretaria de Estado de Meio Ambiente e Sustentabilidade (SEMAS) do Pará (PARÁ, 1997). Com a Portaria no 1.945, de 14 de outubro de 2008, a APA adquiriu Conselho Gestor, de caráter deliberativo. Em 2016, a Portaria no 17, de 10 de fevereiro, alterou a composição do Conselho e, entre outras definições, estabeleceu a competência da APA.

A APA insular encontra-se próxima a ocupações urbanas do centro de Belém, contudo ainda tem características de comunidades tradicionais ribeirinhas que são perceptíveis na organização social, nas atividades de subsistência, nas formas de uso dos recursos naturais, no repasse de conhecimentos para entre gerações, entre outros (COSTA, 2015).

Os principais usos, atividades econômicas e serviços correspondem a residências, estabelecimentos comerciais como bares e restaurantes, estabelecimentos com produção e comercialização de chocolates e produtos regionais. Essas atividades são voltadas para o turismo, que, segundo a população, consiste em uma atividade crescente na Ilha em função do aumento do fluxo de pessoas, principalmente nos finais de semana.

Registram-se outros serviços, como a Escola de Educação Infantil e Fundamental e um posto de saúde, que atendem a algumas necessidades dos moradores locais. De acordo com os residentes da APA insular, os lotes habitados não podem ser vendidos e, por isso, verifica-se que as ocupações são oriundas de famílias que se desmembram para a formação de novos núcleos familiares na localidade.

Os moradores apontaram como um dos principais problemas existentes a dificuldade de acesso à água com qualidade e com segurança, pois esta é julgada inadequada para atividades domésticas e para consumo direto, além de, em alguns trechos, ser insegura para o lazer nos finais de semana.
A diversificação do uso dos recursos hídrico no cotidiano da população ocorre a partir da água do rio, poços amazonas e artesianos, compra de atravessadores vindos de Belém em recipiente de $20 \mathrm{~L}$, captação água da chuva com uso de cisterna e utilização de cacimba (MATTA, 2006; NASCIMENTO et al., 2010; CIRILO, 2013). Por ser considerada um bem comum, foi evidenciada a necessidade de debater alternativas que minimizem as barreiras de acesso à água na APA, garantindo equidade de obtenção desse recurso por todos os moradores da ilha.

Nesse contexto, foi relatado que a movimentação da maré influencia no cotidiano da população da ilha, principalmente em alguns períodos do ano, pois a água do rio chega até as casas localizadas na várzea alta, por isso elas são construídas considerando certa distância do solo. Ressaltou-se, ainda, que o esgotamento sanitário das residências está associado às fossas rudimentares (negras) ou sépticas localizadas perto das habitações, as quais se encontram próximas às margens do rio, e, dessa forma, nos períodos de maré alta a água alcança essas fossas, contribuindo com a carga de matéria orgânica no corpo hídrico.

A influência da maré também foi destacada pelos moradores como outro problema, quando associada à movimentação dos resíduos sólidos urbanos de Belém até a APA, pois o evento afeta a comunidade, principalmente naquelas estruturas que se localizam próximas às margens do Rio Guamá. Evidenciou-se que o movimento diário das marés possibilita o deslocamento dos resíduos sólidos urbanos até as proximidades das residências dos moradores da Ilha do Combu. De acordo com Nascimento et al. (2010), a Comunidade Beira Rio consiste na localidade mais afetada por esse problema. Por outro lado, segundo os relatos, não há serviço público de coleta de lixo na ilha e os resíduos sólidos domésticos provenientes dos residentes da APA não são despejados no corpo hídrico, já que a destinação consiste na queima realizada nos próprios quintais; quando o volume é considerado elevado, os resíduos são transportados para Belém e depositados em coletores na Praça Princesa Isabel. 
Diante do exposto, a dificuldade de acesso à água com qualidade é apontada pelos moradores como uma ocorrência que depende do movimento das marés, já que alcançam as fossas das residências e também transportam resíduos sólidos urbanos de Belém, ocasionando algumas doenças vinculadas ao consumo da água do rio sem o devido tratamento na localidade, apesar de alguns moradores já adotarem métodos de desinfecção por aquecimento da água ou cloração com o uso do hipoclorito como profilaxia para prevenção de doenças.

Além disso, a atividade turística na UC foi apontada como outra problemática que implica no acesso à água. De acordo com Cirilo (2013), o turismo foi intensificado na década de 1990 com o surgimento dos primeiros restaurantes e, posteriormente, outros estabelecimentos iniciaram suas atividades na APA, associados a trilhas ecológicas e passeio fluvial. Os relatos associam à atividade turística o aumento do ruído, o incremento do fluxo e velocidade das embarcações, jet skis e lanchas, o que, por conseguinte, afeta a atividade de pesca, intensifica o processo erosivo nas margens dos rios e prejudica a comunidade ao causar insegurança com possibilidades de acidentes durante o lazer ou perda de material pesqueiro. Outros moradores complementam e mencionam que a atividade turística gera renda para algumas ocupações, contudo a intensificação do tráfego no final de semana traz consequências que levam à modificação na dinâmica da fauna e flora da localidade e provocam alterações na estrutura das residências próximas às margens do rio.

A Figura 3 ilustra o ciclo de Mejía et al. (2012), em que são descritos os principais componentes de análise dos problemas apontados pelos moradores da APA insular, assim como propostas que contribuam para o alcance do propósito da UC, por meio do acesso ao recurso hídrico com qualidade.

1. Meta: garantia das condições de sustentabilidade hídrica para as comunidades que ocupam e vivem (e extraem) dos recursos naturais da Ilha do Combu;

2. Alvo: na elaboração dos estudos básicos, plano de manejo, implantação e funcionamento da APA do Combu, sugere-se a adoção, entre outras, das seguintes medidas: a utilização dos instrumentos legais e dos incentivos financeiros governamentais, para assegurar a proteção e uso racional dos re- cursos naturais; aplicação, quando for necessário, das medidas legais destinadas a impedir ou evitar o exercício de atividades causadoras de sensível degradação da qualidade ambiental, em especial as atividades de derrubada dos açaizeiros, para a retirada do palmito; a divulgação das medidas preventivas, objetivando o esclarecimento do povo, em especial a comunidade local, sobre a APA e suas finalidades (art. 2ㅇ da Lei Estadual no 6.083/1997 — PARÁ, 1997);

3. Resultados descritos na forma de indicadores ferramentas:

- Abastecimento de água - Plano de Abastecimento Público: a llha apresenta várias formas de abastecimento, porém a precariedade destes caracteriza a insustentabilidade do acesso. Tem-se aí o paradigma de se estar cercado por água doce, mas sem condições de uso direto da água para o abastecimento público. A manutenção das condições de sustentabilidade hídrica coloca a necessidade de implantação de um plano de abastecimento local, integrando águas superficiais, subterrâneas e de chuva, como prioritário;

- Geração de efluentes (esgoto) - Sistemas de Coleta e Tratamento de Esgoto: a implantação de fossas rudimentares e o lançamento direto no rio de efluentes causam um impacto imediato no ambiente de várzea, podendo afetar tanto em termos paisagísticos quanto ecológicos. As comunidades devem ter orientação técnica para construção das fossas e o correto lançamento dos efluentes, fatores esses associados à execução de um plano de saneamento;

- Geração e destinação dos resíduos sólidos - Sistema de Gerenciamento de Resíduos Sólidos: os resíduos são gerados sem controle de geração e destinação. A inexistência de um controle de geração e segregação do resíduo na llha de forma sistemática e as diversas soluções adotadas devem ser revistas, principalmente pelo caráter de APA, por meio de um sistema de gerenciamento de resíduos sólidos aplicado às condições locais;

- Doenças de veiculação hídrica - Educação ambiental aplicada ao saneamento: aumento dessas enfermidades é potencializado tanto pelo 


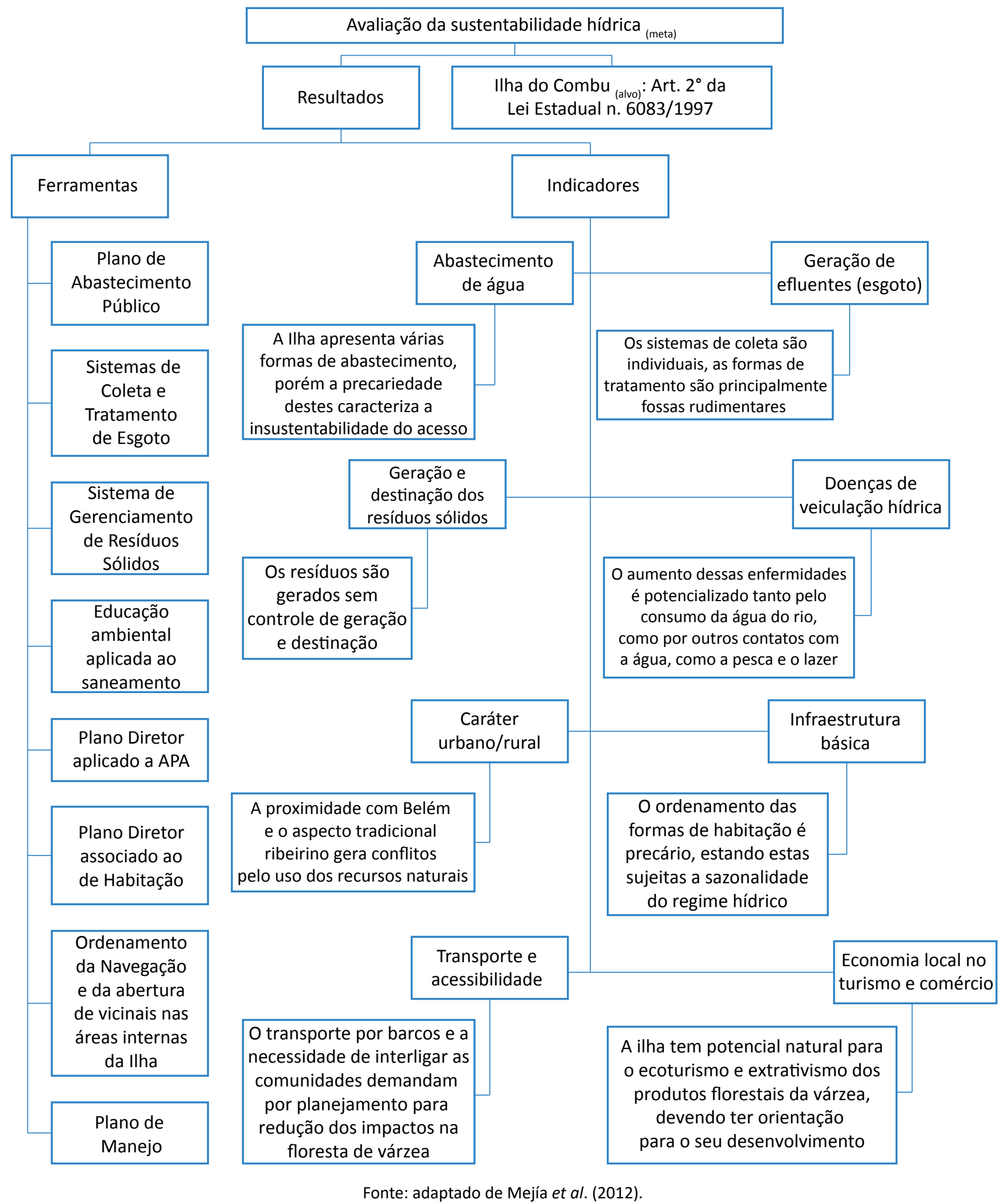

Figura 3 - A sustentabilidade hídrica da llha do Combu. 
consumo da água do rio, como por outros contatos com a água, como a pesca e o lazer. A educação ambiental pode auxiliar nesses aspectos, no sentido de apresentar as condições de risco à saúde e promover o debate acerca do tema;

- Caráter urbano/rural - Plano Diretor aplicado a APA: a proximidade com a capital do Estado (Belém) e a existência de características de comunidades tradicionais ribeirinhas gerando conflitos associados ao uso dos recursos naturais. A biodiversidade local, além das condições relacionadas à segurança pública, é aspecto que a proximidade com o urbano de Belém pode representar uma ameaça. Por isso, a necessidade de um Plano Diretor local que regulamente os elementos de gestão do território;

- Infraestrutura básica - Plano Diretor associado ao de Habitação: o ordenamento das formas de habitação é precário, estando estas sujeitas à sazonalidade do regime hídrico. Associada ao plano diretor tem-se a necessidade de ordenar o processo de habitação local, de modo a atuar também nas consequências diretas do efeito nas marés e dos períodos de extremos de chuvas;

- Transporte e acessibilidade - Ordenamento da Navegação e da abertura de vicinais nas áreas internas da llha: por ser uma APA localizada em área insular, é comum o uso por parte dos moradores locais e turistas do transporte fluvial. O transporte por barcos e a necessidade de interligar as comunidades demandam por planejamento para redução dos impactos na floresta de várzea. O ordenamento permitirá reduzir a ocorrência de portos em áreas ambientalmente sensíveis, estabelecer limite de velocidade e evitar o desmatamento interno na llha para abertura de vicinais;

- Economia local no turismo e comércio - Plano de Manejo: a ilha tem potencial natural para o ecoturismo e extrativismo dos produtos florestais da várzea, devendo ter orientação para o seu desenvolvimento. O Plano de Manejo da Ilha deve ser visto como ação prioritária para adequação dos demais indicadores discutidos, mas especialmente para o ordenamento das atividades econômicas locais, uma vez que, segundo o art. 3o da Lei Estadual no 6.083/1997 (PARÁ,
1997), na APA da Ilha do Combu ficam proibidos ou limitados a implantação e o funcionamento de indústrias potencialmente poluidoras; o exercício de atividades que ameacem extinguir as espécies da biota regional; e o uso de biocidas, quando indiscriminados ou em desacordo com as normas ou recomendações técnicas oficiais.

A sustentabilidade hídrica na Ilha do Combu encontrase ameaçada em um espaço destinado para conservação dos recursos naturais. Portanto, para garantia de qualidade de vida das comunidades e cumprimento do papel de UC para o propósito de preservação/conservação associada ao DS, deve ser implantado um sistema de gestão integrada dos recursos hídricos locais. Segundo a proposta de Mejía et al. (2012), tal sistema estaria baseado na proposta da Pegada Hídrica Azul (HOEKSTRA; CHAPAGAIN, 2007), que implica melhor condição de aproveitamento hídrico local, em que a construção seria continuada visando principalmente aos aspectos fundamentais de: proteção contra riscos naturais e antrópicos, boa governança das águas e acesso à água para todos.

Nesse contexto, entende-se que o envolvimento do Conselho Gestor da APA deve ser considerado para que ele estimule a coesão das comunidades e priorize o interesse coletivo sobre os individuais, quando tratadas as diretrizes da conservação dos recursos naturais e bem-estar social na UC. Além das leis e regras estabelecidas, as propostas sugeridas para a APA devem considerar o contexto local e seguir estratégias bottom up de desenvolvimento endógeno, ou seja, incluir a participação da população local no processo de construção de políticas, planos, programas e projetos que sejam capazes de garantir o desenvolvimento local com autonomia, valorizando os recursos naturais e a cultura local, estimulando a cooperação, solucionando os principais problemas e garantindo qualidade de vida aos moradores (CLEMENTE, 2013; REVEZ, 2014).

Na concepção desse processo, sugere-se a construção de alguns degraus que contribuam para o alcance do desenvolvimento sustentável na APA, partir da sustentabilidade hídrica: a proteção dos serviços ambientais, o balanço dos usos múltiplos das águas, e a consequente redução da pressão antrópica sobre as águas, e a garantia da manutenção dos aspectos qualiquantitativos 
das águas para a manutenção dos ecossistemas locais e atendimento a demanda humana (Figura 4).

Os resultados obtidos resumem as demandas apontadas pelos residentes e pelo conselho gestor, destacas por $\mathrm{Ci}$ rilo e Almeida (2015), Cirilo, Almeida e Rivero (2016) e Lima, Oliveira e Benedita (2018), vinculadas a plano de manejo, problemas de abastecimento de água e saneamento básico, expansão da ocupação, turismo desordenado e fiscalização ambiental. Os temas abordados podem ser associados a discussões mais amplas, como a questão da segurança hídrica (MEKONNEN; HOEKSTRA, 2010; 2011; VOROSMARTY et al., 2010), uma vez observa-se presença forte do setor de comércio e turismo na ilha, o que demanda por água para o desenvolvimento se suas atividades, sendo que o acesso ao recurso é limitado e com um custo social e econômico agregado.

Outra relação observada é da comunidade com as diversas formas de uso água, apontando como consequência a tendência ao potencialmente insustentável, uma vez que questões como saneamento, navegação e ocupação das áreas de várzea estão ocorrendo sem o planejamento adequado em função da capacidade de resiliência da Ilha (STARZYNSKI; SIMÕES, 2015; CORDEIRO et al., 2016; COELHO et al., 2017).

Assim, a sustentabilidade hídrica da llha do Combu depende de ações voltadas à redução do impacto das atividades exercidas sobre as águas, principalmente quanto aos aspectos de qualidade e de integridade dos sistemas hídricos (ALVES; TERESA; NABOUT, 2014; KUHLMANN et al., 2014). Além disso, é necessária a atuação mais emergente na educação para a sustentabilidade (OBARA et al., 2015; POLLI; CAMARGO, 2015), a partir da qual a comunidade poderá construir muitos dos conceitos que vão propiciar a manutenção das condições necessárias à sua moradia (habitação, saúde, segurança, educação, saneamento), a preservação do vasto potencial ecológico da llha (JARDIM; VIEIRA, 2001; JARDIM et al., 2007; QUARESMA; JARDIM, 2012), um dos poucos ambientes característicos de floresta de várzea da foz do Rio Guamá.

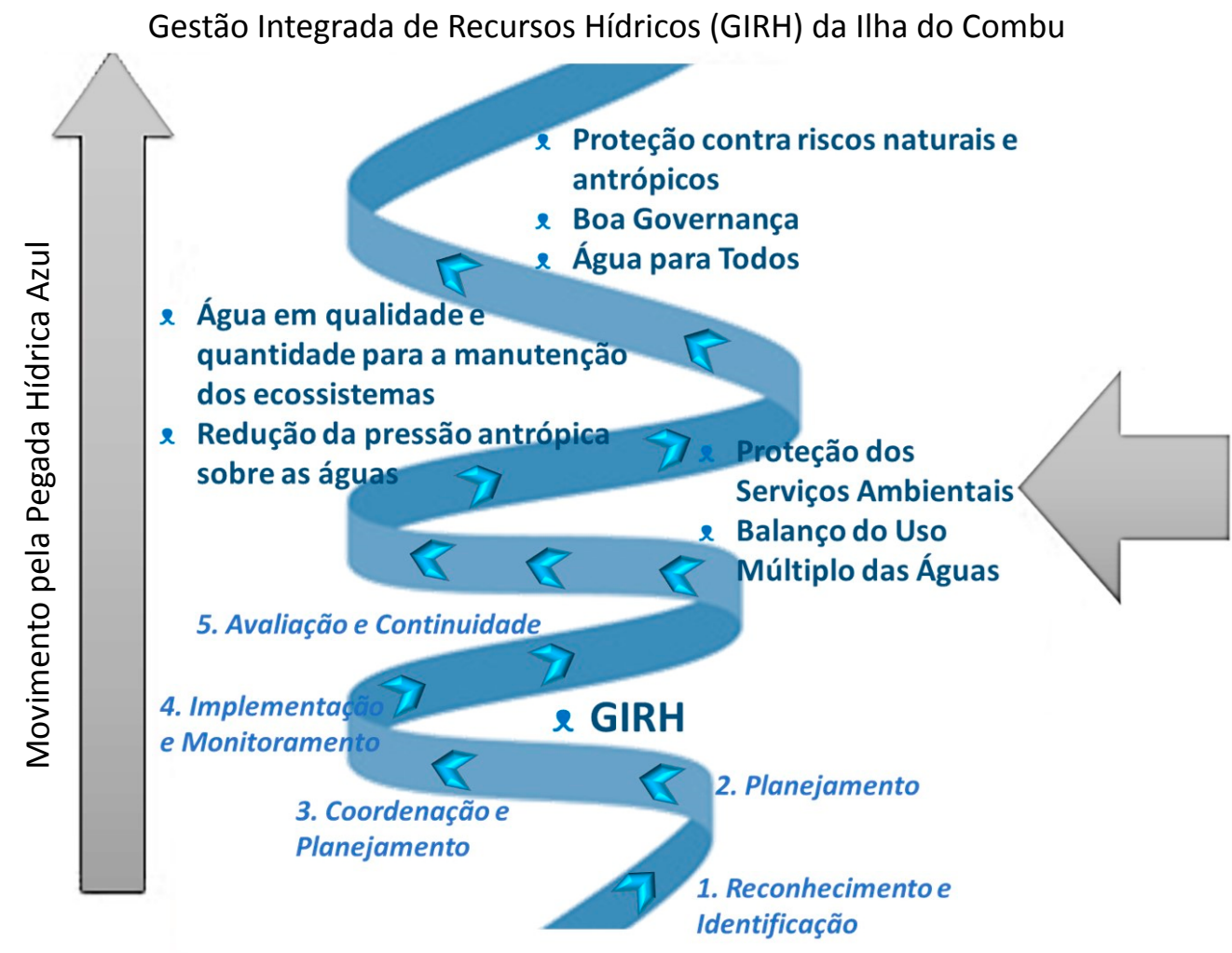

Indicadores que
traduzem condição
de impacto local:
$\leftarrow$ Abastecimento de
água precário
$\leftarrow$ Geração de
esgoto e lixo
$\leftarrow$ Ocorrência de vetores
que causam doenças
de vinculação hídrica
$\leftarrow$ Flutuação do percentual
de ocupação da Ilha pela
proximidade com Belém
$\leftarrow$ Habitações, localização
de portos e abertura de
vicinais em detrimento
da floresta de várzea
$\leftarrow$ Resiliência da floresta de
várzea frente ao turismo
e extrativismo para
manutenção de atividades
econômicas locais

Fonte: adaptado de Mejía et al. (2012).

Figura 4 - Modelo aplicado a gestão integrada dos recursos hídricos da Ilha do Combu. 


\section{CONCLUSÃO}

O estudo demonstrou a dificuldade de garantir o desenvolvimento sustentável, mesmo em espaços físicos criados para alcançar esse propósito. Por outro lado, por meio das problemáticas relatadas pelos moradores, nota-se a necessidade de políticas públicas específicas para APA insular, em razão de ser um espaço destinado à conservação dos recursos naturais, que busca garantir a qualidade de vida da população e a sustentabilidade hídrica, pois a base legal que rege sobre o SNUC no Brasil não faz distinção entre APA de terra firme e de várzea.

Esses aspectos são relevantes para consolidação do processo de desenvolvimento sustentável na UC, pois, no momento, a APA insular analisada sugere um con- texto de vulnerabilidade que precisa ser revertido em prol do bem-estar da população e do meio ambiente.

Por outro lado, torna-se indispensável avaliar e buscar medir o nível de sustentabilidade proposto nos planos, programas e projetos na APA da Ilha do Combu, pois a variação do nível fraco para forte pode estar vinculada ao grau de envolvimento dos moradores em prol da proteção ambiental local.

Finalmente, o planejamento sugerido para gestão hídrica da APA insular tende a contribuir para a proteção ambiental da UC, em um cenário com efetividade na governança ambiental e hídrica, fortificada com base em valores coletivos, coesão e articulação dos moradores.

\section{AGRADECIMENTOS}

Aos moradores da Ilha do Combu que participaram da pesquisa.

Ao Programa de Pós-Graduação em Ciências Ambientais (PPGCA), da Universidade Federal do Pará (UFPA), por incentivar a pesquisa interdisciplinar sobre os problemas socioambientais na Amazônia.

Ao Laboratório de Estudos e Modelagem Hidroambientais (LEMHA), vinculado ao Instituto de Geociências da UFPA, por disponibilizar imagem de satélite utilizada nesta pesquisa.

\section{REFERÊNCIAS}

ABRAHÃO, G. R.; ASMUS, M. L.; FERREIRA, W. Dinâmica da Governança em Unidades de Conservação: Estudo de Caso da Estação Ecológica de Carijós, Florianópolis, Brasil. Florianópolis, Brasil. Revista Costas, v. 1, n. 1, p. 59-86, 2019. http://doi.org/10.26359/costas.0104

ALVES, M. T. R.; TERESA, F. B.; NABOUT, J. C. A global scientific literature of research on water quality indices: trends, biases and future directions. Acta Limnologica Brasiliensia, v. 26, n. 3, p. 245-253, 2014. http://dx.doi.org/10.1590/ S2179-975X2014000300004

BOFF, L. Sustentabilidade: o que é - o que não é. Petrópolis: Vozes, 2012. 199 p.

BRASIL. Agência Nacional de Águas. Cobrança pelo uso de recursos hídricos. Brasília: ANA, 2014.

BRASIL. Lei no 8.617, de 4 de janeiro de 1993. Dispõe sobre o mar territorial, a zona contígua, a zona econômica exclusiva e a plataforma continental brasileira, e dá outras providências. Brasília, 1993.

BRASIL. Lei n. 9.433, de 8 de janeiro de 1997. Institui a Política Nacional de Recursos Hídricos e dá outras providências. Brasília, 1997.

BRASIL. Lei no 9.985, de 18 de julho de 2000. Institui o Sistema Nacional de Unidade de Conservação da Natureza e dá outras providências. Brasília, 2000. 
BRASIL. Agência Nacional de Águas. Cobrança pelo uso de recursos hídricos. Brasília: ANA, 2014.

CAMARGO, D. R. de. Os conceitos de sustentabilidade e desenvolvimento sustentável na produção teórica em educação ambiental no Brasil: Um estudo a partir de teses e dissertações. Dissertação (Mestrado) - Universidade Estadual Paulista "Júlio de Mesquita Filho", Rio Claro, 2016.

CIRILO, B. B. O processo de criação e implementação de Unidades de Conservação e sua influência na gestão local: $O$ estudo de caso da área de proteção ambiental da Ilha do Combu em Belém-PA. Dissertação (Mestrado) - Programa de Pós-graduação em Desenvolvimento Sustentável do Trópico Úmido, Universidade Federal do Pará, Belém, 2013.

CIRILO, B. B.; ALMEIDA, O. T. de. O Conselho Gestor da Área de Proteção Ambiental da Ilha do Combu e a experiência da Gestão Compartilhada. Pará. Estudos Sociais, v. 17, n. 34, 2015.

CIRILO, B. B.; ALMEIDA, O. T. de; RIVERO, S. L. M. O processo de criação e implementação de unidades de conservação e sua influência na gestão local: o caso da Área de Proteção Ambiental da llha do Combu, Estado do Pará. Raízes, v. 36, n. 1, 2016.

CLEMENTE, E. C. Análise da proposta do desenvolvimento territorial na realidade brasileira. GeoAmbiente Online, n. 21, jul./dez. 2013. https://doi.org/10.5216/revgeoamb.v0i21.27911

COELHO, S. C.; DUARTE, A. N.; AMARAL, L. S.; SANTOS, P. M. dos; SALLES, M. J.; SANTOS, J. A. A. dos; SOTERO-MARTINS, A. Monitoramento da água de poços como estratégia de avaliação sanitária em Comunidade Rural na Cidade de São Luís, MA, Brasil. Ambiente \& Água, v. 12, n. 1, p. 156-167, 2017. http://dx.doi.org/10.4136/ambi-agua.1962

CORDEIRO, G. G.; GUEDES, N. de M.; KISAKA, T. B.; NARDOTO, G. B. Avaliação rápida da integridade ecológica em riachos urbanos na bacia do rio Corumbá no Centro-Oeste do Brasil. Ambiente \& Água, v. 11, n. 3, p. 702-710, 2016. http://dx.doi.org/10.4136/ambi-agua.1857

CORREIA, F. Experiências Internacionais de Universalização do Acesso à Água. Brasília, 2013.

COSTA, E. de S.; CASTRO, N. J. C.; SILVA, B. L. A.; SILVA, S. S. S. da. Ilha do Combu: Realidades e desafios. Saúde e Meio Ambiente, v. 4, n. 2, p. 32-48, jul./dez. 2015. https://doi.org/10.24302/sma.v4i2.903

DALHUISEN, J. M.; RODENBURG, C. A.; GROOT, H. L. F.; NIJKAMP, P. Sustainable Water Management Policy: Lessons from Amsterdam. European Planning Studies, v. 11, n. 3, p. 263-281, 2003. https://doi.org/10.1080/09654310303636

DOVERS, S. R.; HANDMER, J. W. Uncertainty, sustainability and change. Global Environmental Change, v. 2, n. 4, p. 262276, 1992. https://doi.org/10.1016/0959-3780(92)90044-8

FINKLER, N. R.; MENDES, L. A.; BORTOLIN, T. A.; SCHNEIDER, V. E. Cobrança pelo uso da água no Brasil: Uma visão metodológica. Desenvolvimento e Meio Ambiente, v. 33, p. 33-49, abr. 2015. http://dx.doi.org/10.5380/dma. v33i0.36413

GLEICK, P. H. Water in Crisis: Paths to Sustainable Water Use. Ecological Applications, v. 8, n. 3, p. 571-579, 1998. https://doi.org/10.1890/1051-0761(1998)008[0571:WICPTS]2.0.CO;2

GREGORY, A.; HALL, M. Urban water sustainability. In: PROSSER, I. P. (org.). Water: science and solutions for Australia. Collingwood: CSIRO, 2011. p. 75-88.

HEINTZ JR., H. T. Applying the Concept of Sustainability to Water Resources Management. Water Resources Update, n. 127, p. 6-10, 2004.

HERING, J. G.; SEDLAK, D. L.; TORTAJADA, C.; BISWAS, A. K.; NIWAGABA, C.; BREU, T. Local perspectives on water. Science, v. 349, n. 6247, p. 479-480, 2015. https://doi.org/10.1126/science.aac5902 
HOEKSTRA, A. Y.; CHAPAGAIN, A. K. Water footprints of nations: water use by people as a function of their consumption pattern. Water Resource Management, v. 21, n. 1, p. 35-48, 2007. https://doi.org/10.1007/s11269-006-9039-x

INSTITUTO BRASILEIRO DE GEOGRAFIA E ESTATÍSTICA (IBGE). Censo Demográfico 2010. Disponível em: <http://www. ibge.gov.br/home/estatística/população/censo2010.shtm>. Acesso em: setembro de 2018.

INSTITUTO DE DESENVOLVIMENTO FLORESTAL E DA BIODIVERSIDADE DO ESTADO DO PARÁ (IDEFLOR-BIO). Portal. Disponível em: <http://ideflorbio.pa.gov.br>. Acesso em: 18 out. 2018.

JARDIM, M. A. G.; SANTOS, G. C. dos; MEDEIROS, T. D. S.; FRANCEZ, D. da C. Diversidade e estrutura de palmeiras em floresta de várzea do estuário amazônico. Amazônia: Ciência \& Desenvolvimento, v. 2, n. 4, p. 67-84, 2007.

JARDIM, M. A. G.; VIEIRA, I. C. G. Composição florística e estrutura de uma floresta da Várzea do estuário amazônico, Ilha do Combu, Estado do Pará, Brasil. Boletim do Museu Paraense Emílio Goeldi, v. 17, n. 2, p. 333-354, 2001.

KRANZ, R.; GASTEYER, S. P.; HEINTZ, T.; SHAFER, R.; STEINMAN, A. Conceptual Foundations for the Sustainable Water Resources Roundtable. Water Resources Update, n. 127, p. 11-19, 2004.

KUHLMANN, M. L.; IMBIMBO, H. R. V.; OGURA, L. L.; VILLANI, J. P.; STARZYNSKI, R.; ROBIM, M. J. Effects of human activities on rivers located in protected areas of the Atlantic Forest. Acta Limnologica Brasiliensia, v. 26, n. 1, p. 60-72, 2014.

LEAL, C. G.; POMPEU, P. S.; GARDNER, T. A.; LEITÃO, R. P.; HUGHES, R. M.; KAUFMANN, P. R.; ZUANON, J.; PAULA, F. R.; FERRAZ, S. F. B.; THOMSON, J. R.; NALLY, R. M.; FERREIRA, J.; BARLOW, J. Multi-scale assessment of human-induced changes to Amazonian instream habitats. Landscape Ecology, v. 31, n. 8, p. 1725-1745, 2016. https://doi.org/10.1007/ s10980-016-0358-x

LIMA, J.; OLIVEIRA, R.; BENEDITA, B. Considerações sobre a gestão e as políticas públicas socioambientais na área de proteção ambiental da Ilha do Combu-PA. In: SEMINÁRIO INTERNACIONAL EM CIÊNCIAS DO AMBIENTE E SUSTENTABILIDADE NA AMAZÔNIA, 5., 2018, Manaus. Anais... Manaus: UFAM, 2018.

MARQUES, R. F. J.; BILAR, A. B. C.; PIMENTEL, R. M. M.; RIBEIRO, E. P. Performance indexes for the fulfillment of conservation units' management. Journal of Environmental Analysis and Progress, v. 2, n. 1, p. 50-60, 2017. https://doi. org/10.24221/jeap.2.1.2017.1034.50-60

MATTA, R. A. de A. Espacialidade e sustentabilidade na llha do Combu: Um olhar sobre a interface urbano-insular como forma de contribuir para a conservação do espaço na construção da sustentabilidade local. Dissertação (Mestrado) Programa de Pós-Graduação em Engenharia Civil, Universidade Federal do Pará, Belém, 2006.

MEJÍA, A.; HUBNER, M. N.; SÁNCHEZ, E. R.; DORIA, M. Water and Sustainability: A Review of Targets, Tools and Regional Cases. Paris: United Nations Educational, Scientific and Cultural Organization, 2012. 52 p.

MEKONNEN, M. M.; HOEKSTRA, A. Y. A global and high-resolution assessment of the green, blue and grey water footprint of wheat. Hydrology and Earth System Sciences, v. 14, p. 12590-1276, 2010. https://doi.org/10.5194/hess14-1259-2010

MEKONNEN, M. M.; HOEKSTRA, A. Y. The green, blue and grey water footprint of crops and derived crop products. Hydrology and Earth System Sciences, v. 15, p. 1577-1600, 2011. https://doi.org/10.5194/hess-15-1577-2011

MUSTIN, K.; CARVALHO, W. D.; HILÁRIO, R. R.; COSTA-NETO, S. V.; SILVA, C.; VASCONCELOS, I. M.; CASTRO, I. J.; EILERS, V.; KAUANO, E. E.; MENDES-JÚNIOR, R. N. G.; FUNI, C.; FEARNSIDE, P. M.; SILVA, J. M. C.; EULER, A. M. C.; TOLEDO, J. J. Biodiversity, threats and conservation challenges in the Cerrado of Amapá, an Amazonian savanna. Nature Conservation, v. 22, p. 107-127, 2017. https://doi.org/10.3897/natureconservation.22.13823 
NAÇÕES UNIDAS. Direito Humano à Água e ao Saneamento: Resolução da Assembleia Geral n 64/292, aprovada em 28 de julho de 2010. Nova lorque, 2010.

NASCIMENTO, E. P. Trajetória da sustentabilidade: do ambiental ao social, do social ao econômico. Estudos Avançados, v. 26, n. 74, p. 51-64, 2012. http://dx.doi.org/10.1590/S0103-40142012000100005

NASCIMENTO, N. S. do; FARIAS, M. S.; LIMA, N. G. de; MIRANDA, R. S. Um estudo dos problemas ambientais da Área de Proteção Ambiental da Ilha do Combu Belém - PA. In: CONGRESSO BRASILEIRO DE GESTÃO AMBIENTAL, 1., 2010. Anais... Bauru, 2010.

OBARA, A. T.; KOVALSKI, M. L.; REGINA, V. B.; RIVA, P. B.; HIDALGO, M. R.; GALVÃO, C. B.; TAKAHASHI, B. T. Environmental education for sustainable management of the basins of the rivers Pirapó, Paranapanema III and Parapanema IV. Brazilian Journal of Biology, v. 75, n. 4, supl. 2, p. 137-147, 2015. http://dx.doi.org/10.1590/1519-6984.01113suppl

PARÁ. Lei no 6.083, de 13 de novembro de 1997. Dispõe sobre a criação da Área de Proteção Ambiental da Ilha do Combu no Município de Belém. Belém, 1997.

PIZELLA, D. G.; SOUZA, M. P. de. Análise da Sustentabilidade ambiental do Sistema de Classificação das águas doces superficiais brasileiras. Engenharia Sanitária e Ambiental, v. 12, n. 2, p. 139-148, abr./jun. 2007. http://dx.doi. org/10.1590/S1413-41522007000200005

POLLI, G. M.; CAMARGO, B. V. Representações Sociais do Meio Ambiente e da Água. Psicologia: Ciência e Profissão, v. 35, n. 4, p. 1310-1326, 2015. http://dx.doi.org/10.1590/1982-3703001622013

PRUGH, T.; ASSADOURIAN, E. What is sustainability, anyway? World Watch, v.16, n. 5, p. 10-21, 2003.

QUARESMA, A. C.; JARDIM, M. A. G. Diversity of epiphytic bromeliads in the environmental protection area of Combu Island, Belém, Pará, Brazil. Acta Botanica Brasilica, v. 26, n. 2, p. 290-294, 2012. http://dx.doi.org/10.1590/S010233062012000200006

REVEZ, J. Papel das Associações de desenvolvimento local e regional, como estrutura organizacional e funcional inovadora de gestão no desenvolvimento local: A experiência portuguesa do Alentejo. Desenvolvimento Regional em Debate, v. 4, n. 2, p. 115-139, jul./dez. 2014. https://doi.org/10.24302/drd.v4i2.683

SACHS, I. Caminhos para o desenvolvimento sustentável. 2. ed. Rio de Janeiro: Garamond, 2009. 95 p.

SACHS, I. Rumo à socioeconomia: teoria e prática do desenvolvimento. São Paulo: Cortez, 2007.

SANTOS, C. A. P. dos; SOUZA, J. S.; SOUZA, A. L. A.; SANTOS, V. C. P. O papel das políticas públicas na conservação dos recursos naturais. Revista Geográfica Acadêmica, v. 10, n. 2, 2016. http://dx.doi.org/10.18227/1678-7226rga. v10i2.3570

SARTORI, S.; LATRÔNICO, F.; CAMPOS, L. M. S. Sustentabilidade e Desenvolvimento Sustentável: Uma taxonomia no Campo da Literatura. Ambiente e Sociedade, São Paulo, v. 17, n. 1, p. 1-22, jan.-mar. 2014.

SECRETARIA DE ESTADO E MEIO AMBIENTE (SEMA). Portaria no 1.945, de 14 de outubro de 2008. Dispõe sobre a criação do Conselho Gestor. Belém, 2008.

SECRETARIA DE ESTADO E MEIO AMBIENTE (SEMA). Portaria no 17 de 01 de fevereiro de 2016. Dispõe sobre a alteração do Conselho Gestor e estabelece a competência da APA Combu. Belém, 2016.

STARZYNSKI, R.; SIMÕES, S. J. Avaliação quantitativa do uso dos recursos hídricos em unidade de conservação: estudo de caso do Parque Estadual Serra do Mar. Sociedade \& Natureza, v. 27, n. 2, p. 327-340, 2015. http://dx.doi. org/10.1590/1982-451320150210 
STOFFEL, J. A.; COLOGNESE, S. A. O Desenvolvimento Sustentável sob a ótica da sustentabilidade multidimensional. Revista FAE, Curitiba, v. 18, n. 2, p. 18-37, jul./dez. 2015.

THOMAS, P. T. Proposta de uma Metodologia de Cobrança pelo Uso da Água vinculada à Escassez. Tese (Mestrado em Ciências em Engenharia Civil) - Universidade Federal do Rio de Janeiro, Rio de Janeiro, 2002.

TISDELL, C. Local communities, conservation, and sustainability: Institutional change, altered governance and Kant's social philosophy. International Journal of Social Economics, v. 24, n. 12, p. 1361-1375, 1997. https://doi. org/10.1108/03068299710193877

TODOROV, V.; MARINOVA, D. Models of Sustainability. In: WORLD IMACS / MODSIM CONGRESS, 18., 2009. Cairns. Anais... Cairns, 2009.

VARELA, L. H. F. Desafios ao direito humano à água e à sustentabilidade dos serviços em Santa Cruz, Cabo Verde. Ambiente e Sociedade, São Paulo, v. 19, n. 1, p. 209-228, jan./mar. 2016. http://dx.doi.org/10.1590/18094422asoc150167r1v1912016

VOROSMARTY, C. J.; MCINTYRE, P. B.; GESSNER, M. O.; DUDGEON, D.; PRUSEVICH, A.; GREEN, P.; GLIDDEN, S.; BUNN, S. E.; SULLIVAN, C. A.; LIERMANN, C. R.; DAVIES, P. M. Global threats to human water security and river biodiversity. Nature, v. 467, n. 7.315, p. 555-561, 2010. https://doi.org/10.1038/nature09440 